\title{
Cruise Terminal Traffic Organization Methods with Multiple Berths in China
}

\author{
Chen $\mathrm{Li}^{1}$ \\ ${ }^{1}$ CCCC Third Harbor Consultants Co. Ltd., Shanghai, China
}

Keywords: Multiple Berths; Cruise Terminal; Traffic Organization Methods; CHINA

\begin{abstract}
In recent years, the demand of optimizing traffic organization have been more and more urgent at the relevant cruise terminals with the rapid development of China's cruise economy. Cruise travel is new to China. China Cruise tourists are significantly different from Europe and America in the cruise Terminal traffic behavior. To solve the problem of traffic organization is to enhance the service level of tourist service satisfaction and promote the sustainable development of the cruise terminals. In this paper, the traffic organization methods with multiple berths are verified by the simulation model, which are brought into the construction scheme and have achieved good practical results.
\end{abstract}

\section{Introduction}

Since the beginning of 2006, China's cruise industry has become the focus of the global cruise industry in ten years. The world's top four cruise group continues to attach importance to the Chinese market; cruise guests number record highs in recent years. According to statistics, in 2016 the China major cruise port received a total of 955 cruise ships, an increase of 428\% compared to 2010 (in 2010 record 223 times), the average annual growth rate of $71.4 \%$; the entry and exit of cruise passengers reached 4 million 390 thousand passengers, an increase of 556\% compared to 2010 (in 2010 record 790 thousand times), the average annual growth of $92.6 \%$.

In 2017, along with the Princess Cruise's "Majestic Princess" and Norway's really cruise " Norwegian Joy" debut, China port is expected to have 18 cruises in homeport routes for deployment, and most of them are more than 100000GRT cruise with average standard capacity of more than 2000 people. With development of cruise market in Chinese area so quickly, the port will require departments to complete planning and quality management for traffic organization.

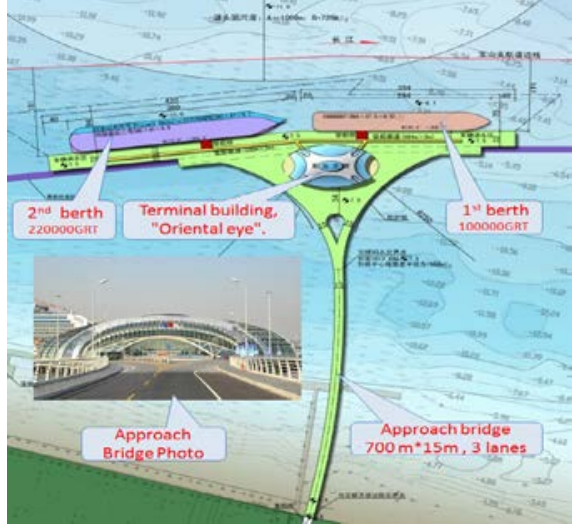

Fig.1 Present Situation of SWICT

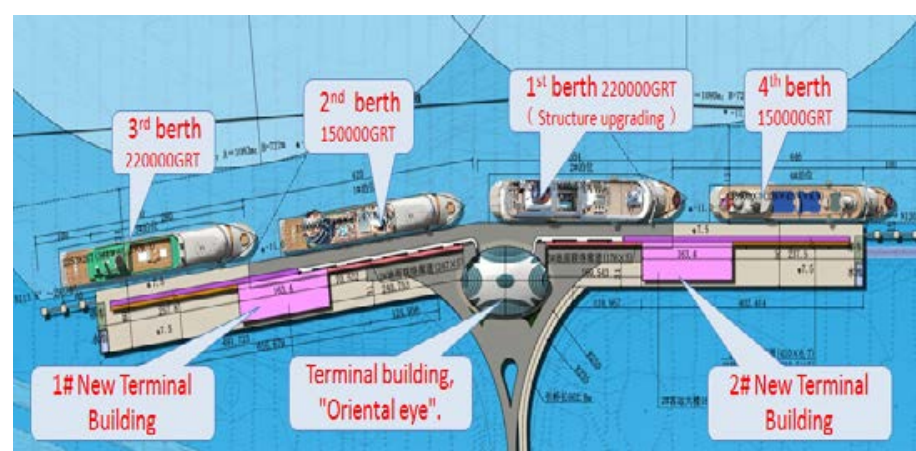

Fig.2 General Layout of Phase 2nd Project

\section{Background}

In 2016 Shanghai Wusongkou International Cruise Terminal（SWICT） received 494 cruise ships, cruise passengers number reached 2 million 200 thousand; respectively accounted for $51.7 \%$ and 50.1\% for China. SWICT existing 2 large cruise berths, 1st for 100000GRT vessels and 2nd for 220000GRT vessels with area of 22 thousand square of the terminal building, called the "Oriental eye". The approach bridge length is about $700 \mathrm{~m}$ with $15 \mathrm{~m}$ wide. There are 3 lanes in the approach 
bridge in 10.5m roadway, 1 lane for entry , 1 lane for exit and 1 Lane for taxi storage. Thus are shown in Fig.1.

At the end of 2017, SWICT phase 2nd is expected to be completed with 2 new berths. There are two 150000GRT and two 220000GRT cruise berths in total at the end of 2017 with 2 new terminal building areas of 23 thousand square meters each. Thus are shown in Fig.2.

Both of the size of the cruise market and the port construction scale, the port is a typical multi berths cruise terminal in China.

China cruise traffic behavior characteristics. Larger proportion of early tourist. According to the statistics for $\mathrm{t}$ SWICT, general proportion of early tourist is about $25 \%-55 \%$. The proportion can reach $45 \%-70 \%$ in new ship or new route. And such indicator in the Caribbean is generally less than $50 \%$.

The impact of China's cruise product sales policies and regulations. In China cruise product sales is in the model contract by the travel agent wholly or partly.

At the same time, "People's Republic of China tourism law" stipulates that travel agencies organize outbound travel and inbound tourism team, should arrange the tour guides throughout. According to the above situation, the proportion of bus traffic during the entry and exit of cruise tourists is higher, with an average of about $45 \%$.

China cruise tourists age characteristics. The average age of China's cruise tourists is about 42 years old, compared to Europe and the United States consumers younger.

However, the overall perception of cruise tourism over the age of 40 was significantly better than that of other age groups. Especially those aged from 41 to 50 and those over the age of 60, these 2 age groups had the highest level of awareness. Over the age of 50 respondents, the proportion of participated in the cruise travel is more than $40 \%$, under the age of 40 respondents, the proportion of participated in the cruise travel is less than $30 \%$. So for age of Chinese cruise tourist present two levels of differentiation.

Elderly people like to take bus or taxi and shuttle vehicles. Young people generally take a bus or a taxi and car parking. According to statistics the proportion of pick-up vehicles and Parking vehicles is about $15 \%$ and $8 \%$. Parking ratio is in an upward trend year by year.

SWICT Current traffic facilities situation. Current status of port traffic organization. Exit period: allow all types of vehicles (taxis, private cars, travel agencies bus, shuttle bus, etc.) get on the pier. Not divided in types of vehicles at curbside platform with about 100 parking spaces.

Entry period: Do not allow pick-up the vehicle getting on the pier directly.

When the tourist get off the ship, go to the designated area and inform the vehicle, the entry of pick-up can be allowed with certificate inform. Allow other vehicles (taxi, tour bus, shuttle bus, etc.) on the pier. Simple divided in types of vehicles at curbside platform

curbside platform. In the operation of a single ship tourists get on/off vehicle is under control. But in the two ships of the same by (both for the first period, the departure area) the curbside platform is very crowded with 60-70 taxi storage capacity. It's long queue, long time waiting and low service level. Thus are shown in Fig.3-6.

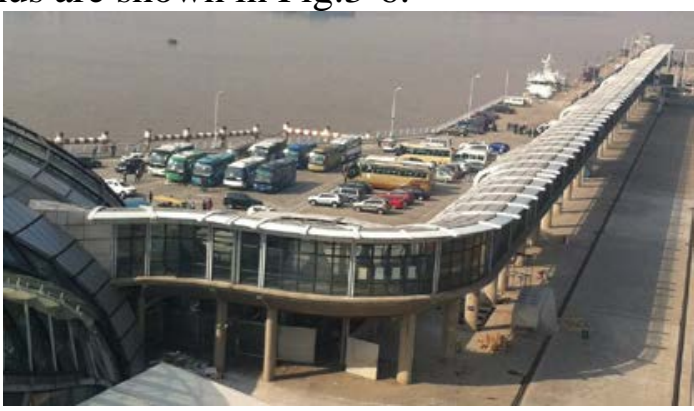

Fig.3 Small Bus Parking Area

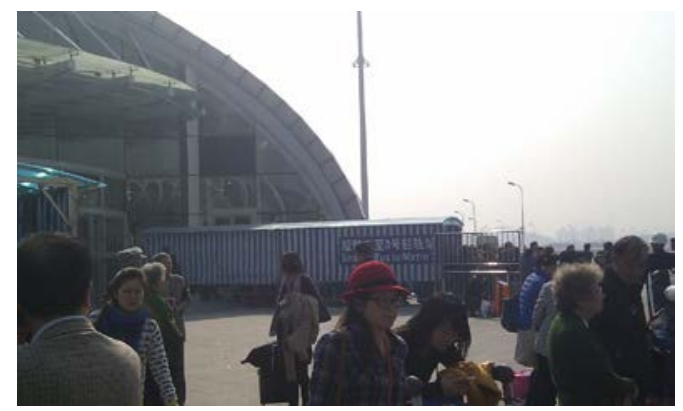

Fig.4 Congestion at Shuttle Bus (To Rail Transport) Waiting Area 


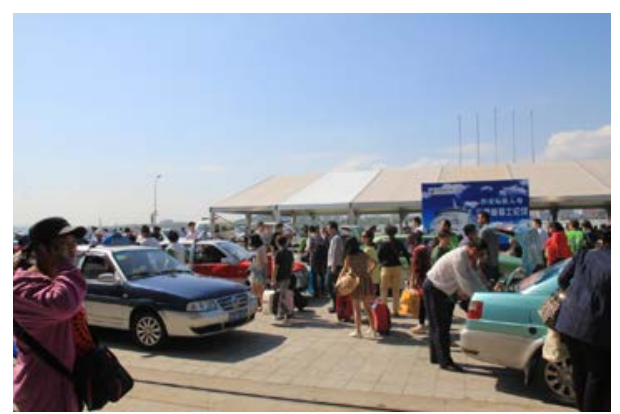

Fig.5 Congestion at Taxi Waiting Area

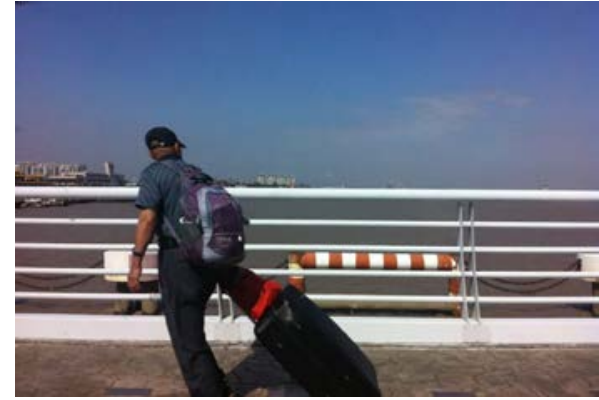

Fig.6 Some Tourists Walk Out Of the Harbor with Dragging the Luggage

Parking area. Existing cruise port external parking area can only provide about 100 car parking spaces. Single ship barely support, it (both for homeport) cannot meet the requirements of two ships at the same time.

So a large number of vehicles park at the side of main road out of cruise port, which further affects the comprehensive transportation capacity. Thus are shown in Fig.7.

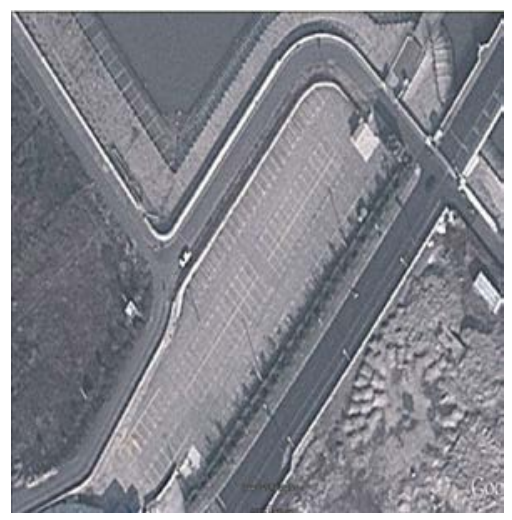

Fig.7 Parking Resources

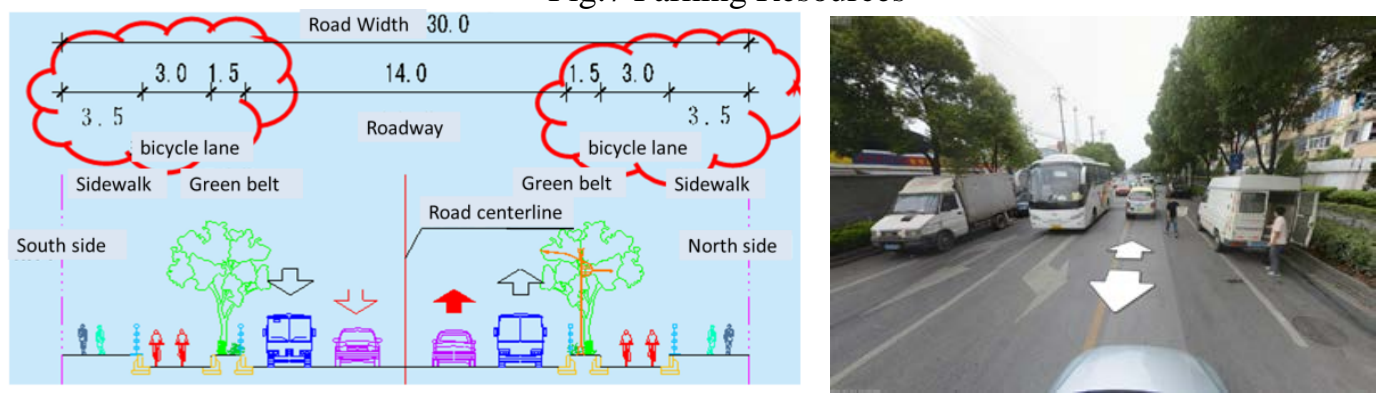

Fig.8 Section and Real Situation of Baoyang Rd

External traffic restriction. Road Traffic Capacity. The main road outside the port is Baoyang Road, which is the twin four-lane at present. But with a large number of vehicles park at the side of Baoyang Road, which further affects the comprehensive transportation capacity. Thus are shown in Fig.8.

Railway Transport. The railway transport Out of SWICT is line 1st and line 3rd of Shanghai Shentong Metro Group Co., Ltd. At this stage, the railway transport traffic load is relatively well, two ships of the same time is also not very crowded.

But after the construction of SWICT project phase $2^{\text {nd }}$, there will be four ships berthing at the same time there are. There is the possibility of deterioration of railway transport conditions.

\section{Literature Review}

YANG Wei-jia (2013) states that, based on the design of the traffic organization on Shanghai Wusongkou cruise homeport, he compares $\mathrm{M} / \mathrm{M} / \mathrm{N}$ and $\mathrm{N}-\mathrm{M} / / \mathrm{M} / 1$ queuing system models in passenger border inspection and analyze the experience of different queuing model. He develops a 
kind of preliminary optimal control approach of interest between passengers and border inspection is proposed.

WANG Song and CHEN Juehao(2014) suggest to improve the relevant policies of regional cruise traffic; do not integrate The regional and home port transportation traffic network and Building a seamless system for seaport and Airport.

\section{Methodology}

In this paper, I find out 10 factors of cruise terminal traffic organization methods with multiple berths by analyzing above-mentioned, and seek key points through independent judgments by shipping companies, terminal companies, tourists, travel agencies, designers.

According to the table above, the key points of the comprehensive traffic of the multi - berth cruise port are as follows:

Differences in the size of the vehicle, the design scale of the vehicle has not yet unified

Complex operating method

Bias in tourist traffic choice forecast

Different in vehicle parking time

Vehicle arrival time is not clear

External road capacity restriction

The parking area is too small

\section{Countermeasures}

According to the typical vehicle parameters, unify the design of the vehicle scale and parking spaces. The main vehicles in the cruise port are the tourist bus, shuttle bus, management vehicles, supply vehicles and transport vehicles. By understanding the main models of various types of vehicles, this paper puts forward the main vehicle parameters and the design of parking spaces.

Determine Design Operating Conditions. Through comprehending the requirement of cruise and combined with the previous work of Harbor Company, as well as the future development trend of cruise ports, we clear the following design operating status:

Status of four ships at the same time: 3 homeport vessels (2 ships of 220000GRT and 1 ship of 150000GRT) and 1 port-of-call vessel (ships of 220000GRT).

The design homeport passenger number is combined 100\% tourists and $70 \%$ crew members. The design port-of-call passenger number is $95 \%$ tourists.

Visitor Traffic Choice Forecast. Traffic choice of outbound tourists. The vehicle of Homeport routes is combined by 30\% Tourist vehicles, $25 \%$ taxi and $45 \%$ travel bus. The vehicle of port-of-call routes is $100 \%$ travel bus.

Traffic choice of inbound tourists. The vehicle of Homeport routes is combined by $15 \%$ Tourist vehicles, $15 \%$ taxi, $25 \%$ shuttle bus and $45 \%$ travel bus. The vehicle of port-of-call routes is $100 \%$ travel bus.

Different Types Of Vehicles Stopping Time For Tourists In Different Operating Conditions. By refining the characteristics of various types of vehicles operating in the port, we get the following data:

Departure period of homeport

Travel bus average stopping time is $5-15 \mathrm{~min}$.

Shuttle bus average stopping time is $4-8 \mathrm{~min}$ (at pier).

Tourists' vehicles stopping time is $1-3 \mathrm{~min}$.

Taxi stopping time is $1-2 \mathrm{~min}$.

Arrival period of homeport

Travel bus average stopping time is $10-30 \mathrm{~min}$.

Shuttle bus average stopping time is $4-8 \mathrm{~min}$ (at pier).

Tourists' vehicles stopping time is $1-3 \mathrm{~min}$. 
Taxi stopping time is $1-2 \mathrm{~min}$.

The period of entry and exit of port-of-call routes

Travel bus average stopping time is $5-15 \mathrm{~min}$.

Vehicle Arrival Time Distribution. Based on the related statistical analysis of Actual operation situation, this paper puts forward the behavior curve of inbound tourists for a 100000GRT ship. So we can calculate the time distribution of the arrival time of all kind vehicles with the visitor traffic choice forecast. And for other classes of ships can be deduced too. Thus are shown in Fig.9.

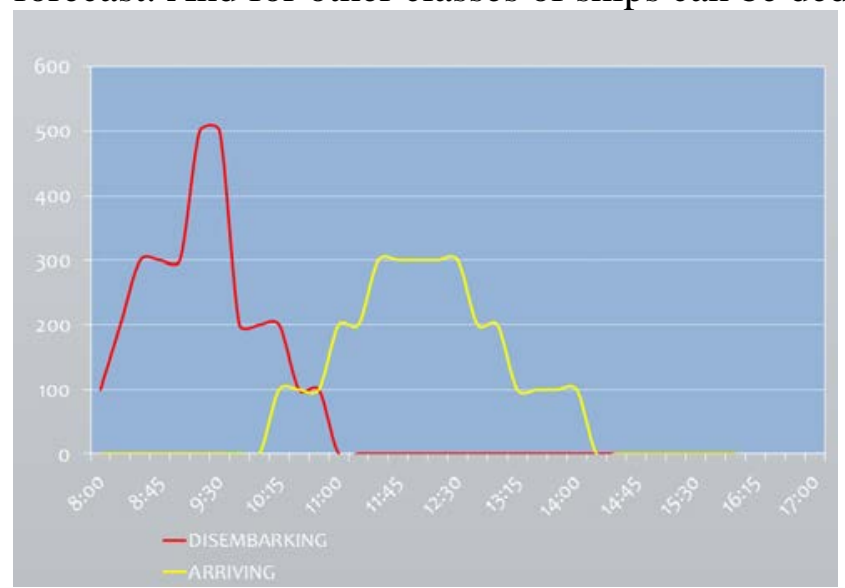

Fig.9 100000 GRT Ship’s Tourist Arrival and Departure Curve

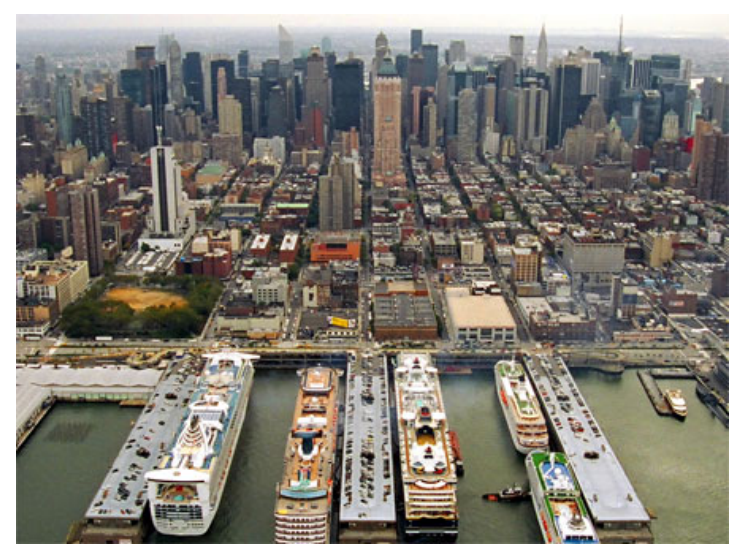

Fig.10 Aerial View of Manhattan Cruise Terminal's Pier 88-91

Research Set Up Parking Lot In The Building Or At The Roof . According to the experience of foreign related projects, this paper puts forward the function to set up parking lot in the building or at the roof.

In the terminal building, setting up function of parking lot in the building or at the roof, can satisfy the tourists parking requirement, improve the port traffic organization level, reduce road traffic peak, optimize and improve the comprehensive service level of harbor, and increase the port's operating income. There are a lot of foreign cruise ports setting up parking lot in the building or at the roof. Thus are shown in Fig.10.

In SWICT 2nd project, we set social parking lot at the roof of terminal building with a total of about 500-1000 large and small car parking spaces.

Detailed design can be considerate in accordance with the code for fire protection design of garage, motor-repair-shop and parking-area (GB 50067-97).

In addition, a 3M-high parapet is arranged at the roof, which can shade the car and improve the sight of building from outside. But this panel cannot solve the problem of bad visual impact from the ship.

External Road Capacity Restriction Outside The Harbor. Through getting in touch with transportation departments of Shanghai city and Baoshan district :the docking two urban, we put forward the following suggestions for Shanghai Wusongkou international cruise port external traffic planning:

Underground tunnel of BaoYang Road. Proposed planning and construction of the underground tunnel of BaoYang Road, which connect Tongji Road in West and cruise port in East. The underground tunnel is a total length of about $2.3 \mathrm{~km}$, the roadway of two-way 4 lanes, only car can pass, buried depth of about $7 \mathrm{~m}$. The main roadway of underground tunnel is connected with the underground parking garage of the port. Thus are shown in Fig.11.

Other related road construction planning. There are a lot of important transportation road behind SWICT, such as BaoYang road, Binjiang Ave., Mohe road and tanghou road.

Through the expansion and opening of the relevant roads, it can undertake the secondary traffic flow for the cruise port traffic, to provide more comprehensive protection for port operations. Thus are shown in Fig.12. 
Rapid transit system (bus, tramcar, elevated car etc.). The rapid transit system is one of the important ways of tourists' transportation in cruise port. Proposed planning fast and convenient, high quality, medium volume and area minimization rapid transit system in the Binjiang area which SWICT located, in order to improve proportion of public transport of cruise port, reduce overall road traffic volume, as soon as giving consideration to Binjiang area tourism function.
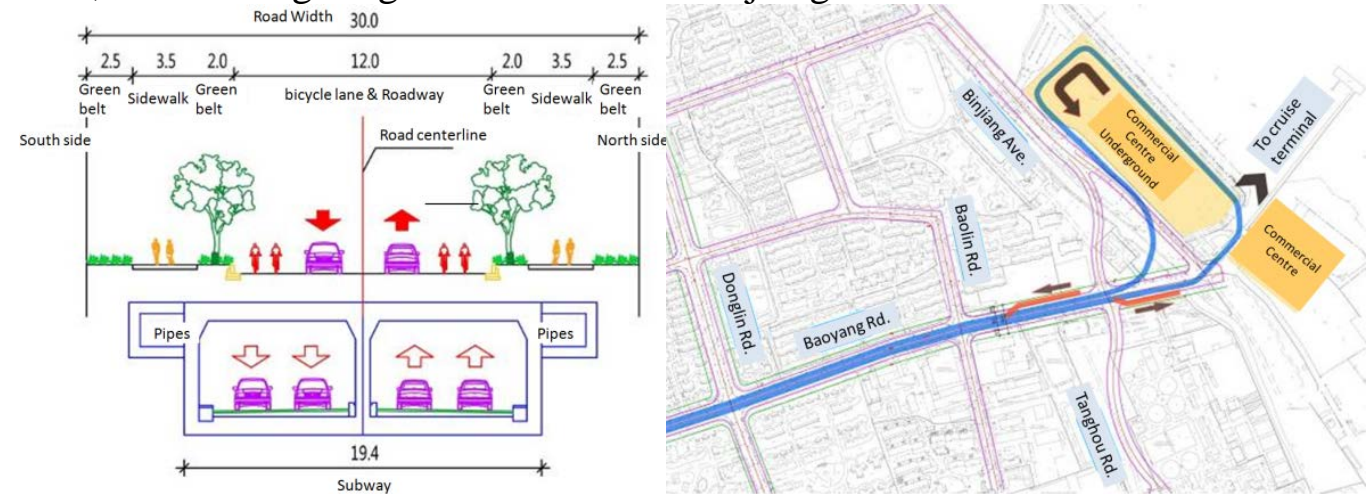

Fig.11 Underground Tunnel Planning Of Baoyang Rd

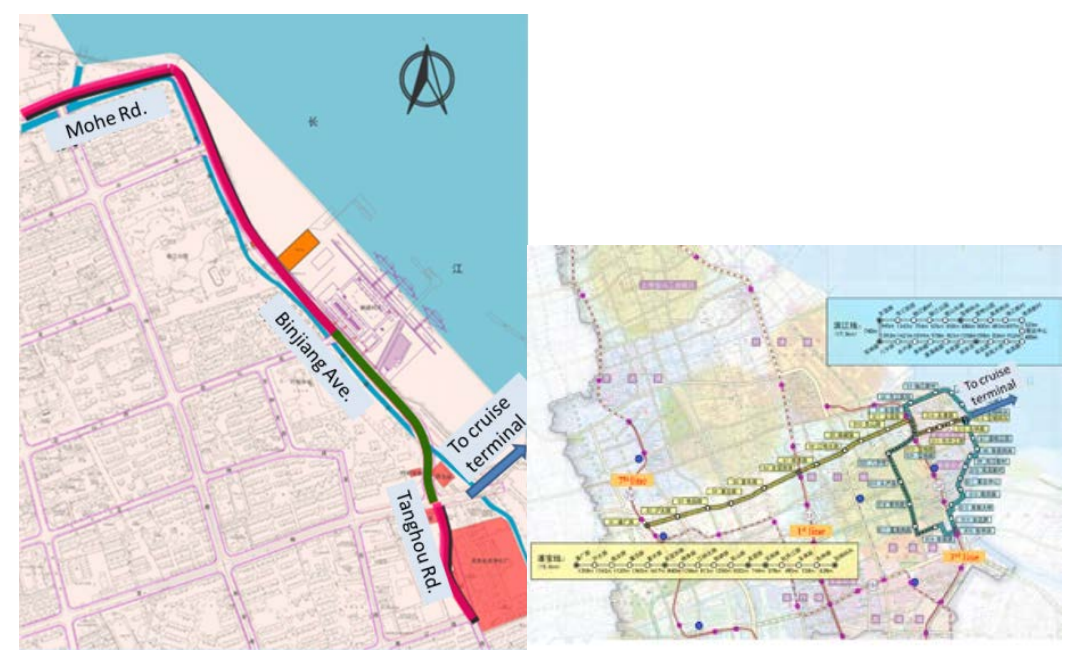

Fig.12 Related Road Construction Plans

Fig.13 RTS Layout Planning Organization

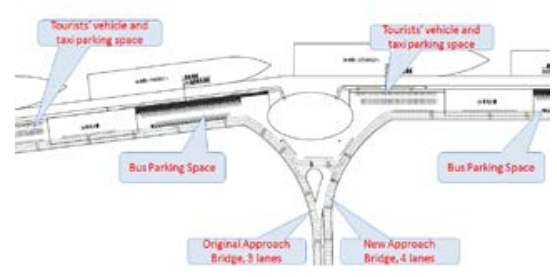

Fig.14 General Layout of Traffic

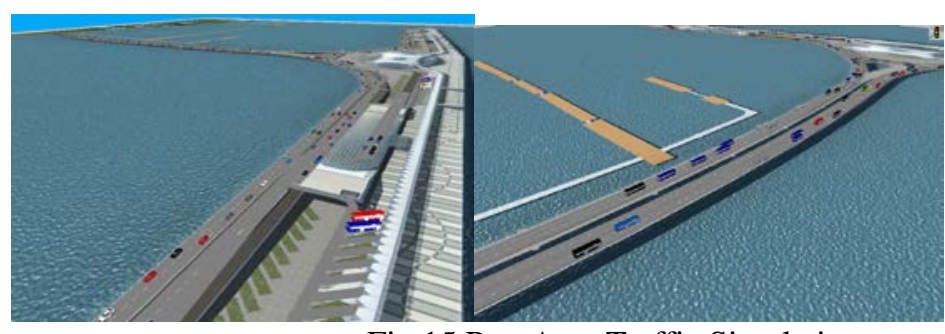

Fig.15 Port Area Traffic Simulation

Planning A (PanBao line): Along the Panguang road establish ties with line 7th ,line 1st and line 3rd of Shanghai Shentong Metro Group Co, connecting the main large residential area and Baoshan economic and administrative center, meeting the commuting and transfer function requirement.

Planning B (Binjiang line): Around the Binjiang New District and the transformation Wusong District, Binjiang line will support the future of Baoshan's most important cultural tourism business development. Thus are shown in Fig.13.

Traffic organization scheme. According to the requirements of various operating conditions, in accordance with the results of traffic volume, we have built a new approach bridge, which is close to the original approach bridge and is basically parallel. 2 approach bridge have 7 lanes, 3 lanes for entry , 3 lanes for exit 1 Lane for taxi storage. 
We divided into the east and west breaches when the vehicles enter the terminal area with each breach arranged 4 lanes, 2 in and 2 out. The roads of each breaches are arranged Ring Road, one-way traffic, no crossing.

The approach bridge peak hour conversion traffic demand is 2483PCU/h.

Based on the calculated results it need 25 tourists vehicle parking space, 31 taxis parking space and 78 bus parking space in curbside. In general layout we arrange 111 tourists' vehicle and taxi parking space and 117 bus parking space in curbside. Thus are shown in Fig.14.

\section{Traffic Simulation Model Validation}

Simulation model software. In this paper, VISSIM software is used to model validate the Traffic organization scheme.

VISSIM software is a kind of simulation modeling tools based on micro, time interval and driving behavior. It can analyze operation condition of all kinds of traffic behavior under various traffic conditions through lane setting, vehicle structure, traffic signals, bus stations, etc. It is an effective tool for program evaluation of traffic engineering design and city planning. Thus are shown in Fig.15.

Conclusions of the simulation model. After the simulation, i the traffic flow is Smooth and parking spaces meet the use requirements in the traffic organization scheme.

\section{Conclusion}

With the Center of the world cruise market gradually moves eastward, the Asia Pacific market, especially China, has become the focus of attention of many international cruise companies.

Therefore, Based on the rapid development of China's cruise economy the demand for port traffic organization optimization is becoming more and more urgent in the next few years.

So to solve the problem of traffic organization is not only an important breakthrough for the development of environment friendly strategy in the cruise port, but also is to enhance the service level of port and tourist service satisfaction, which can achieve an important starting point for the sustainable development of the cruise port.

In this paper, the related integrated traffic countermeasures are verified by the model, and are put into practice in the SWICT 2nd project.

Through this strategy it enhances the level of port service, improve the tourist experience and promote the development of cruise economy in the Asia Pacific region. This strategy can extend to River Cruise ports and other cruise port to enhance China's comprehensive strength of the port in the future.

\section{References}

[1] YANG Wei-jia, (2013), Random Queuing System on Arrival Process of Cruise Home Port Customers. Port \& Waterway Engineering, 484(10), 263-266

[2 ]WANG Song and CHEN Juehao, (2014), Study On Regional Transportation Design of Cruise Home Port. Tourism Overview, 2014(2), 311-312 